\title{
EXAMINATION OF (PHENOTHIAZINYL)VINYL-PYRIDINIUM DYE'S CAPACITY OF INTERACTION WITH DNA
}

\author{
BIANCA STOEAN ${ }^{a *}$, LUIZA GAINA ${ }^{a}$, EMESE GALa, \\ CASTELIA CRISTEA ${ }^{a}$, TAMAS LOVASZ ${ }^{a}$ and \\ LUMINITA SILAGHI-DUMITRESCUa
}

\begin{abstract}
The interaction of (E)-4-(2-(7-bromo-10-ethyl-10Hphenothiazin-3-yl)vinyl)-1-methylpyridin-1-ium (PVP) dyes with calf-thymus DNA was examined by spectrophotometric UV-vis absorption/emission titration and competitive ethidium bromide displacement. The association constant values were situated in $10^{6} \mathrm{M}^{-1}$ range, typical to cationic dyes containing the monocyanine chromophore system. The variation of the counterion of the cationic PVP dye from iodide to tetrafluoroborate produced dissimilarities in the interaction pattern with DNA. The PVP iodide competitively displaced the ethidium bromide (EB) from the EB-DNA system, thus suggesting the intercalation ability of the dye, while the PVP tetrafluoroborate did not supported the intercalation of the dye.
\end{abstract}

Keywords: cyanine dyes, phenothiazine, DNA binding, association constant

\section{INTRODUCTION}

Synthetic organic compounds which may bind non-covalently to cellular DNA attracted a constantly growing scientific attention [1]. An important group of organic compounds that interact reversibly with the DNA double helix are the intercalators (small molecules inserted within the hydrophobic space between two adjacent DNA base pairs) considered as key compounds for the discovery of new anti-tumor agents based on the assumption that intercalation disrupt replication and/or transcription processes eventually leading to apoptosis of tumor cells rich in DNA. On the other hand, organic

\footnotetext{
a Babeş-Bolyai University, Faculty of Chemistry and Chemical Engineering, 11 Arany Janos str., RO-400028, Cluj-Napoca, Romania

*Corresponding author: sba2488@chem.ubbcluj.ro
} 
dyes which bound specifically to DNA were proved to be very useful in fluorescence microscopy applications designed for visualization of DNA by staining cells of various origins (plants, animals, bacteria and viruses) (e.g. ethydium bromide (EB), 4',6-diamidino-2-phenylindole (DAPI) [2]). Relaying on the structural features of the organic compound involved in the intercalation course, the interaction with the DNA macromolecules may occur by three different paths: (i) electrostatic interactions with phosphate groups of nucleotides, (ii) inclusion between base pairs of the two strands (iii) intercalation in the grooves of the double helix [3, 4]. As a consequence, DNA intercalators may exhibit three essential structural features: i) a polyaromatic system involving fused planar rings (chromophore) binding with DNA. ii) Cationic species which increase the efficiency of DNA intercalators by interaction with the negatively charged DNA sugar-phosphate backbone. iii) Groove binding side chains, which can occupy the minor groove of DNA [5,6]. The experimental methods most extensively used for measuring the DNA binding interactions were: isothermal titration calorimetry (ITC), competition dialysis, ethidium bromide displacement, absorbance and fluorescence titration [5].

Phenothiazine derivatives have a long history behind with leading representatives in pharmaceuticals (bactericides, neuroleptic drugs), dyes and fluorophores. Continuing our preoccupation for the characterization of new phenothiazine-based fluorophores [7-10] and chromophores with binding affinity towards nucleic acids [11-13], in this work we examined the capacity of interaction of (phenothiazinyl)vinyl-pyridinium (PVP) dyes [14] with DNA. The selection of the target PVP dyes for this study was guided by the presence of prerequisite basic pharmacophoric structural features (as indicated in Figure 1) completed by our previous finding that these dyes display intense fluorescence emission inside the B16-F10 murine melanoma cells [15].

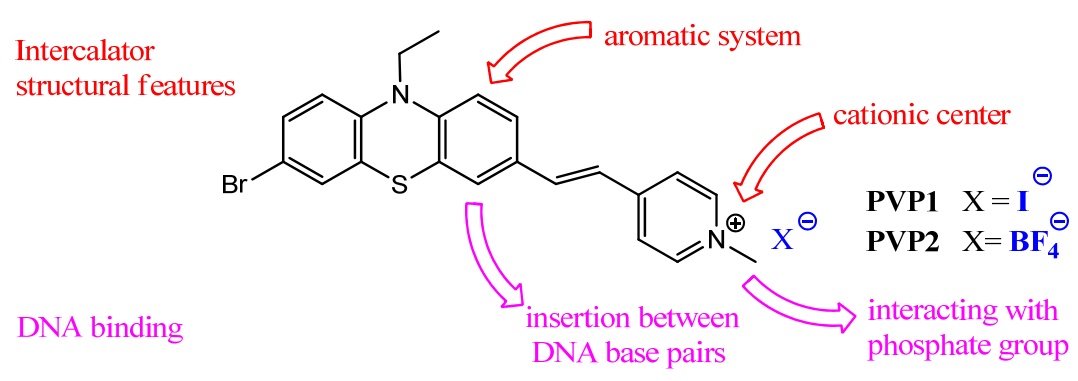

Figure 1. Structural formula of PVP dyes in this study and structural features prerequisite for interaction with DNA 


\section{RESULTS AND DISCUSSION}

The dyes selected for this study, (E)-4-(2-(7-bromo-10-ethyl-10Hphenothiazin-3-yl)vinyl)-1-methylpyridin-1-ium iodide (PVP1) and (E)-4-(2(7-bromo-10-ethyl-10H-phenothiazin-3-yl)vinyl)-1-methylpyridin-1-ium tetrafluoroborate (PVP2) contain the same chromophore system belonging to the class of cyanine dyes, but are differentiated by the nature of the counterion. It is known that the presence of iodide anion can induce the quenching of cyanine dyes fluorescence in solution due to photo-induced electron transfer from iodide to the dye's LUMO, a fact which was also observed in the case of PVP1 which appeared fluorescent only in solid state or in the cytosol where the ion exchange overrides the quenching effect [15]. Upon exchanging the counterion to tetrafluoroborate, PVP2 displayed an emission maximum situated at $605 \mathrm{~nm}$ $\left(10^{-8} \mathrm{M}\right)$ in DCM solution [15]. Both compounds are stable in the buffer solution used in the CT-DNA titration, fact proven by UV-vis absorption spectra of dye PVP1 in TRIS-EDTA solution $\left(10^{-5} \mathrm{M}\right)$ after $0,30,60,90$ minutes irradiation with UV radiation $\lambda=365 \mathrm{~nm}$ [15].

\section{UV-vis absorption titration}

The binding of small molecules to DNA produces a hypochromic effect, a broadening and a red shift of the complex absorption band. These effects are particularly pronounced for intercalators. In order to evaluate the affinity of PVP dyes for binding nucleic acids, UV-vis spectra were recorded during PVP titration with increasing amounts of Calf Thymus-DNA (ctDNA). As it can be seen in Figure 2, the increase of the ctDNA concentration resulted in a continuous decrease of the intensity of the absorption maxima of PVP1. The noticeable hypochromic effect (up to 28\%) and the bathochromic shift of the absorption maxima from 450 to $470 \mathrm{~nm}$, are supporting an interaction of PVP1 with the double stranded helix [16, 17].
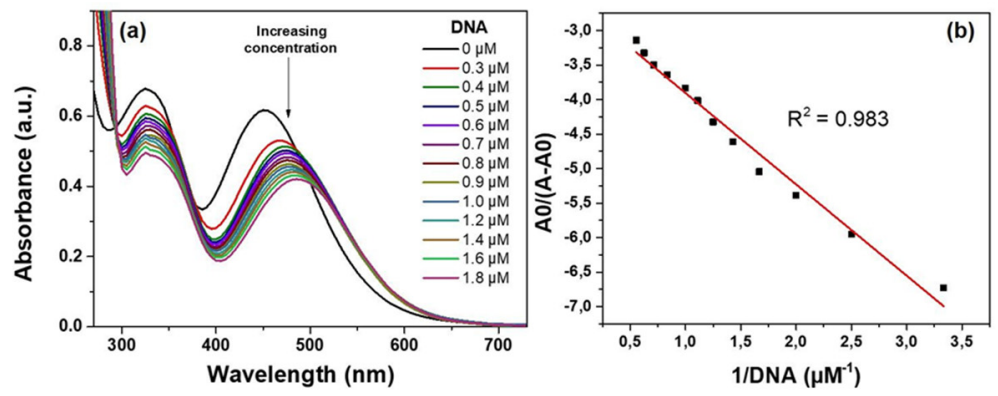

Figure 2. Interaction of PVP with ctDNA a) UV-vis absorption spectra of PVP1 $(5 \mu \mathrm{M}$,$) in 0.01 \mathrm{M}$ Tris-HCl buffer $(\mathrm{pH} 7.4)$ in the presence of increasing amounts of ctDNA (0.3-1.8 $\mu \mathrm{M}$ from top to bottom) b) plot of the variation in absorbance of PVP1 in the presence of ctDNA 

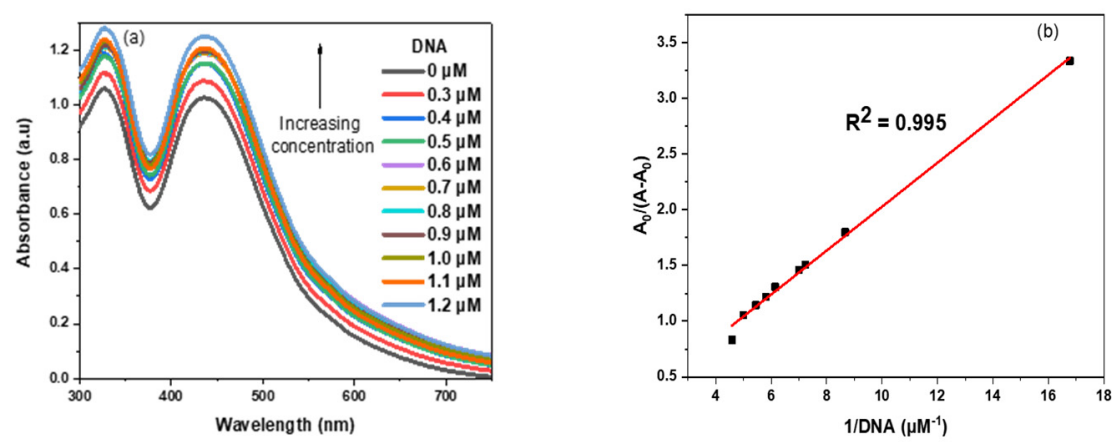

Figure 3. a) UV-vis absorption spectra of PVP2 $(5 \mu \mathrm{M})$ in $0.01 \mathrm{M}$ Tris-HCl buffer $(\mathrm{pH} 7.4)$ in the presence of increasing amounts of ctDNA $(0.3-1.8 \mu \mathrm{M}$ from top to the bottom) b) plot of the variation in absorbance of PVP2 in the presence of ctDNA

From the variation of spectrophotometric absorption of PVP2 depicted in Figure 3 it can be seen that the change of the counter ion from iodine to the bulky tetrafluoroborate is accompanied by a major change in the way of interaction with the ctDNA. The hyperchromic effect recorded for the molar extinction maxima situated at $436 \mathrm{~nm}$ and the $2 \mathrm{~nm}$ blue shift are specific for the interaction with the external part of the DNA, most likely through electrostatic interactions [18].

Based on the variation in absorbance of PVP in the presence of DNA, the association constants for PVP-ctDNA systems were determined according to Benesi-Hildebrand equation (1) from the intercept-to-slope ratio of variation of absorbance versus reciprocal DNA concentration plot presented in figures $2 \mathrm{~b}$ and $3 \mathrm{~b}$ respectively [3].

$$
\frac{\mathrm{A}_{0}}{\mathrm{~A}-\mathrm{A}_{0}}=\frac{\varepsilon_{0}}{\varepsilon-\varepsilon_{0}}+\frac{\varepsilon_{0}}{\varepsilon-\varepsilon_{0}} \cdot \frac{1}{\mathrm{~K}[\mathrm{DNA}]}
$$

where: $K$ is the association constant, $A_{0}$ is the absorbance of PVP, $A$ is the absorbances of the PVP-ctDNA complex, $\varepsilon_{0}$ and $\varepsilon$ are the molar extinction coefficients of the PVP and the PVP-ctDNA complex, respectively.

The calculated association constant values depicted in Table 1, are indicating that PVP1-2 are exhibiting association constants of the same order of magnitude as several monomethine cyanine dyes derived from 2thiomethylbenothiazolium and 4-methylquinolinium salts [18] and higher than the values reported for phenothiazinium intercalators such as Methylene Blue $\left(\mathrm{K}=2.13 \times 10^{4} \mathrm{M}^{-1}\right)[19]$. 
Table 1. Association constants for PVP-ctDNA

\begin{tabular}{|c|c|}
\hline System & $\mathrm{K} \times 10^{5}\left(\mathrm{M}^{-1}\right)$ \\
\hline PVP1-ct-DNA & 19.5 \\
\hline PVP2-ct-DNA & 18.4 \\
\hline
\end{tabular}

\section{Fluorescence emission titration}

The direct fluorometric titration of PVP2 in the presence of increasing amounts of ctDNA was applied. As it can be seen in Figure 4, the increase of the ctDNA concentration produced an increase of the fluorescence intensity but without any shift of the emission maxima. A similar behavior was reported for many cyanine dyes [18].

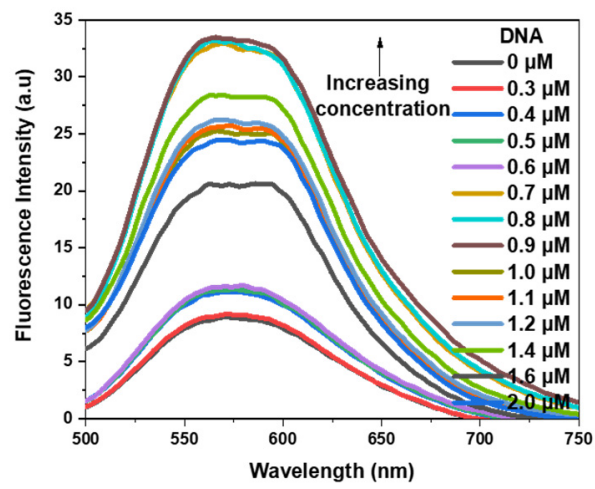

Figure 4. Fluorescence emission spectra of PVP2 $(5 \mu \mathrm{M})$ in $0.01 \mathrm{M}$ Tris- $\mathrm{HCl}$ buffer ( $\mathrm{pH} 7.4)$ in the presence of increasing amounts of ctDNA

(0.3-2 $\mu \mathrm{M}$ from bottom to the top)

\section{Competitive binding between ethidium bromide (EB) and PVP for DNA}

Ethidium bromide (EB) is a sensitive fluorescence probe with a planar structure that binds DNA by an intercalative mode. The fluorescence of EB increases after DNA intercalation. Due to the fact that PVP dye does not display fluorescence emission in solution, its ability to competitively displace the bounded EB-DNA, was explored by fluorescence spectroscopy [18]. PVP intercalation into DNA may determine a decrease in the binding sites of DNA available for EB, thus decreasing the fluorescence intensity of the EB-DNA system. 
As it can be seen in Figure 5 a presenting the fluorescence emission spectrum of EB-ctDNA system upon titration with PVP1, the decrease in fluorescence intensity of the emission maxima situated at $606 \mathrm{~nm}$ correlates with the increase in the concentration of PVP1, suggesting that PVP1 may interact with EB-ctDNA by displacing the EB fluorophore.
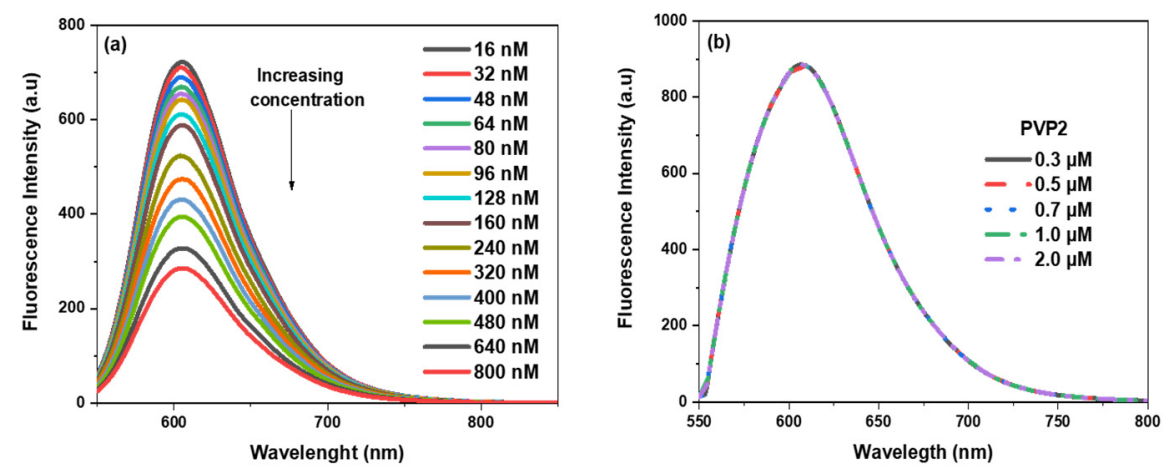

Figure 5. Fluorescence emission spectra of the EB-ctDNA system upon titration with PVP1 in Tris- $\mathrm{HCl}$ buffer $(\mathrm{pH} 7.4), \lambda_{\mathrm{ex}}=518 \mathrm{~nm}$, [EB] $=8.3 \times 10^{-9} \mathrm{~mol} / \mathrm{L}$, [ct-DNA] $=2.5 \times 10^{-7} \mathrm{~mol} / \mathrm{L},[\mathrm{PVP} 1]=16 \times 10^{-9}-800 \times 10^{-9} \mathrm{~mol} / \mathrm{L}$ from top to bottom. b) fluorescence emission spectra of the EB-ct-DNA system upon titration with PVP2 in Tris-HCl buffer ( $\mathrm{pH} 7.4), \lambda_{\mathrm{ex}}=518 \mathrm{~nm},[\mathrm{~EB}]=8.3 \times 10^{-9} \mathrm{~mol} / \mathrm{L}$, [ct-DNA] $=2.5 \times 10^{-7} \mathrm{~mol} / \mathrm{L},[\mathrm{PVP2}]=0.3 \times 10^{-6}-2 \times 10^{-6} \mathrm{~mol} / \mathrm{L}$

As it may be seen in Figure $5 b$, in the presence of increasing amounts of PVP2 the fluorescence emission spectrum of EB-ctDNA complex does not show any change neither in intensity nor in the position of the emission maximum, therefore, this compound cannot effectively replace EB in the EBDNA complex, bringing a support that PVP2 may be faintly bound to DNA.

\section{CONCLUSIONS}

The interactions of PVP with ctDNA studied by using UV-vis absorbance spectroscopy revealed an association constant PVP-ctDNA in the $10^{6}$ range. Based on fluorescence spectroscopic data the interaction of PVP2 with ctDNA is not of a classical intercalator, further confirmed by EB displacement experiments. 


\section{EXPERIMENTAL SECTION}

All the materials for experiments, reagents and solvents were obtained from commercial suppliers and used without further purification. PVP1 and PVP2 dyes were synthesized according to our previously reported procedure [15].

UV-vis absorption spectra were recorded with a Perkin Elmer Lambda 35 spectrophotometer. UV-vis emission spectra in solution were recorded using a Perkin Elmer LS55 spectrophotometer.

\section{DNA Binding experiments}

The ctDNA was purchased from Alfa Aesar, the ethidium bromide $1 \%$ water solution and $\mathrm{HCl}$ were purchased from Merck. All solutions were prepared using double-distilled water. Tris- $\mathrm{HCl}$ buffer solution was prepared from (tris-(hydroxymethyl)-amino-methane-hydrogen chloride) and $\mathrm{pH}$ was adjusted to 7.4 by dropping $\mathrm{HCl}$ concentrated solution. The stock solution of ctDNA was prepared by dissolving $1.75 \mu \mathrm{L}$ of DNA $(170 \mu \mathrm{M})$ in $3 \mathrm{~mL}$ of Tris- $\mathrm{HCl}$ buffer ( $\mathrm{pH} 7.4)$. The concentration of nucleotide was determined by UV spectrophotometry at $260 \mathrm{~nm}$ wavelength, using the molar extinction coefficient $\varepsilon=6600 \mathrm{M}^{-1} \mathrm{~cm}^{-1}$.

\section{ACKNOWLEDGMENTS}

This work was supported by a grant of Romanian Ministry of Research and Innovation, CNCS - UEFISCDI, project number PN-III-P4-IDPCCF-2016-0142.

\section{REFERENCES}

1. L. Strekowski, B. Wilson, Mutat Res, 2007, 623(1-2), 3-13

2. A. Kurutos, I. Balabanov, F.S. Kamounah, K. Nikolova-Ganeva, D. Borisova, N. Gadjevd, T. Deligeorgiev, A. Tchorbanov, Dyes Pigm., 2018, 157, 267-277

3. Z. Rehman, A. Shah, N. Muhammad, S. Ali, R. Qureshi, A. Meetsma, I. S. Butler, Eur J Med Chem, 2009, 44, 3986-3993

4. J.T. Petty, J.A. Bordelon, M.E. Robertson, J Phys Chem B, 2000, 104, 72217227

5. L.V. Smith, J.M. de la Fuente, K.M. Guthrie, A.D.C. Parentya, L. Cronin, New J. Chem., 2005, 29, 1118-1120 
6. K. El-Adl, M.K. Ibrahim, M.S.I. Alesawi, I.H. Eissa, Bioorg. Med. Chem., 2021, 30, 115958

7. E. Gal, B. Brem, I. Pereteanu, L. Gaina, T. Lovasz, M. Perde-Schrepler, L. Silaghi-Dumitrescu, C. Cristea, L. Silaghi-Dumitrescu, Dyes Pigm., 2013, 99(1), 144-153

8. B. Brem, E. Gal, L. Gaina, C. Cristea, A.M. Gabudean, S. Astilean, L. SilaghiDumitrescu, Dyes Pigm., 2015, 123, 386-395

9. L. Gaina, E. Gal, L. Mataranga-Popa, D. Porumb, A. Nicolescu, C. Cristea, L. Silaghi-Dumitrescu, Tetrahedron, 2012, 68(11), 2465-2470

10. L. Gaina, T. Lovasz, I.A. Silberg, C. Cristea, S. Udrea, Heterocyclic Communications, 2001, 7(6), 549-554

11. I.H. Filip, E. Gal, I. Lupan, M. Perde-Schrepler, P. Lonnecke, M. Surducan, L. Gaina, E. Hey-Hawkins, L. Silaghi-Dumitrescu, Dalton Trans, 2015, 44, 615629

12. L. Gaina, L. Mataranga-Popa, E. Gal, P. Boar, P. Lonnecke, E. Hey-Hawkins, C. Bischin, R. Silaghi-Dumitrescu, I. Lupan, C. Cristea, L. Silaghi-Dumitrescu, Eur J Org Chem, 2013, 2013, 5500-5508

13. E. Molnar, E. Gal, L. Gaina, C. Cristea, E. Fischer-Fodor, M. Perde-Schrepler, P. Achimas-Cadariu, M. Focsan, L. Silaghi-Dumitrescu, Int. J. Mol. Sci., 2020, 21, 3178

14. L. Gaina, I. Torje, E. Gal, A. Lupan, C. Bischin, R. Silaghi-Dumitrescu, G. Damian, G., P. Lönnecke, C. Cristea, L. Silaghi-Dumitrescu, Dyes Pigm., 2014, 102, 315-325

15. B. Stoean, D. Rugina, M. Focsan, A-M. Craciun, M. Nistor, T. Lovasz, A. Turza, I-D. Porumb, E. Gal, C. Cristea, L. Silaghi-Dumitrescu, S. Astilean, L. I. Gaina, Int. J. Mol. Sci., 2021, 22, 2985-3006

16. D. Jin, B. Wang, Y. Hou, Y. Du, X. Li, L. Chen, Dyes Pigm., 2019, 170, 107612

17. S. Kashanian, J. Ezzati, N. Dolatabadi, Food Chem, 2009, 116, 743-747

18. J. Zhao, W. Li, R. Ma, S. Chen, S. Ren, T. Jiang, Int. J. Mol. Sci., 2013, 14, 16851-16865 